\title{
Multiplicative Structural Decomposition Analysis of Spatial Differences in Energy Intensity among G20 Countries
}

\author{
Yang Wang ${ }^{1}$, Meng Sun ${ }^{2}$, Rui Xie ${ }^{2, *}$ and Xiangjie Chen ${ }^{2, *}$ \\ 1 School of Business Administration, Hunan University, Changsha 410082, China; yangwanghnu@yahoo.com \\ 2 School of Economics and Trade, Hunan University, Changsha 410079, China; sm971017@163.com \\ * Correspondence: xrxrui@hnu.edu.cn (R.X.); xiangjiechen@hnu.edu.cn (X.C.); Tel.: +86-186-8467-5789 (R.X.); \\ +86-155-7495-0433 (X.C.)
}

Received: 19 February 2020; Accepted: 13 April 2020; Published: 19 April 2020

\begin{abstract}
Comparing the spatial differences in the energy intensity of the Group of Twenty (G20) countries and identifying the factors that influence these differences can help the G20 countries formulate targeted policies to achieve energy conservation goals. This study analyzes the spatial differences in the G20 countries' energy intensity at the aggregate and sectoral levels based on an input-output framework and reveals its driving factors by employing multiplicative structural decomposition analysis, obtaining the sectoral energy intensity, input structure, and final demand structure effects. The results show that: (1) the gap in aggregate energy intensity among the G20 countries tended to converge from 2000 to 2014 with the reducing energy intensity in Russia, India, China, and South Korea having great potential to reduce global energy consumption and improve global energy efficiency; (2) in 2014, the main driving forces for above-average energy intensity was the sectoral energy intensity effect in India, South Korea, and Canada, the input structure effect in Russia and China, and the final demand structure effect in Indonesia; (3) using the average of the G20 countries as a reference, the energy reduction potential of China, Russia, India, South Korea, Indonesia, and Canada is $62.75,31.94,21.24,7.67,1.47$, and 0.81 exajoules (EJ), respectively. The embodied energy consumption decline in these countries was equivalent to $21.78 \%$ of the G20's total energy consumption in 2014; and (4) the most important factor of the high embodied energy intensity of key sectors in India and South Korea is the sectoral energy intensity effect, while for Russia and China, it is the input structure effect.
\end{abstract}

Keywords: energy intensity; input-output analysis; multiplicative SDA; G20 countries

\section{Introduction}

The rapid development of the world economy is increasing the pressure on energy supply and discovering methods for cleaner industrial production has become crucial. Sustainable development requires balancing economic growth, energy consumption, and the resulting environmental impacts [1]. The aggregate intensity of energy consumption, defined as the energy consumed per unit of gross domestic product (GDP), has been recommended as a tool for evaluating the aggregate performance of energy utilization and climate change mitigation [2]. In 2018, the G20 countries accounted for 86\% of the global economic economy [3] and $82 \%$ of total primary energy consumption [4]. Thus, the G20 countries not only serve as the backbone of the global economy, but their energy efficiencies also determine global energy consumption. In a joint effort to address the challenges of global climate change and sustainable development, the G20 countries, excluding the United States, signed an agreement in 2019 to ensure the full implementation of the Paris Agreement. Since the G20 includes 
both developing countries with high energy intensity and developed countries with low energy intensity, comparing the energy intensity of the G20 countries and analyzing the influencing factors can help us identify the key industries in high-energy-intensity countries that could contribute to improving energy intensity governance.

Studies have mainly explored the influencing factors of energy intensity at the national level, and the research methods employed primarily include index decomposition analysis (IDA) and structural decomposition analysis (SDA). In IDA, the decomposition results can be expressed in additive and multiplicative forms. Generally, the additive form is applied to the absolute change in the total index, while the multiplicative form is applied to the relative change [5-7]. A commonly used form of IDA is logarithmic mean Divisia index (LMDI) [8-13]. Ang [14] proposes eight LMDI models and their decomposition methods, as well as their advantages and disadvantages. Since the LMDI method can only reflect direct effects, Su and Ang [15] combine the multiplicative Dietzenbacher and Los (D\&L) [16] method with a multiplicative LMDI to study the factors that influenced China's carbon emission intensity changes from 2007 to 2012 at the national level, final demand category, and sectoral level, providing a satisfactory solution to the industry segmentation effect problem. Lin and Du [17] combine IDA with production-theoretical decomposition analysis to identify and quantify the dynamics of energy intensity changes in Chinese provinces from 2005 to 2010. In Wang et al. [18], the extended LMDI method is used to decompose the changes in China's total industrial energy intensity into macro and technical factors using data from 36 industrial sectors in China from 2003 to 2015.

Compared with IDA, the combined input-output (I-O) model used for an I-O SDA can quantify not only the direct economic and technological links between national industries, but also the indirect links. I-O SDA separates the factors that affect the economic, energy, and environmental systems and quantifies the contribution of the factors to the energy intensity. The authors of $[6,19,20]$ analyze the differences between IDA and SDA. Wang et al. [20] highlight that, for the intensity indicator, multiplicative decomposition is generally preferred to additive decomposition due to the ease of result presentation and greater suitability for tracking purposes. Zhang et al. [21] uses I-O SDA to investigate the contributions of changes in the energy mix, sectoral energy efficiency, production structure, final demand structure, and final demand category composition to China's energy intensity fluctuations during 1997-2007.

Based on the original additive SDA method, Su and Ang [7] explore multiplicative SDA, which has been widely used since their seminal work. In addition to being used for comparative static analysis, multiplicative SDA can also be used for spatial difference analysis. The development of the multiplicative SDA method has enabled decomposition analysis at the aggregate and sectoral levels. The main decomposition method used in multiplicative SDA is the multiplicative D\&L method [16], which is similar to the generalized Fisher's index method in the IDA [22]. Initially, D\&L could only be used to obtain decomposition results at the aggregate level. Su and Ang [23] then introduced attribution analysis, estimating the contribution of each department at the sectoral level. Su and Ang [7] introduce four models for calculating a country's aggregate intensity using the I-O framework, which includes taking the I-O model, decomposition method selection, imports assumption, and GDP calculation method into account, and they further improve the multiplicative SDA framework. The authors of [24] refine the multiplicative SDA framework and define it as a spatial SDA. Zhou et al. [25] use the three-layer SDA method to analyze the main driving factors of energy intensity changes in China. However, few studies use spatial SDA to analyze differences in carbon intensity, energy intensity, or other environmental indicators between regions.

In summary, the literature mainly focuses on the driving factors behind intertemporal changes in energy intensity in various countries and lacks comparative studies on international differences in energy intensity as well as the causes of these differences. Considering the current state of research in this area, this study's contributions are as follows. (1) We first analyze the spatial differences in energy intensity among the G20 countries at the aggregate and sectoral levels. (2) By employing the multiplicative SDA method, we decompose the driving factors of energy intensity differences 
among the G20 countries into sectoral intensity, input structure, and final demand structure effects. Further, we evaluate the energy reduction potential for selected high-energy-intensity countries. (3) Considering the differences in energy intensity among sectors, we use multiplicative SDA to decompose the embodied energy intensity (EEI) drivers of key sectors and further identify the correlations between key sectors that drive the differences in energy intensity among the G20 countries.

The remaining paper is organized as follows. Section 2 explains the theoretical model and data used in this study. Section 3 shows the spatial differences in energy intensity among the G20 countries at the aggregate and sectoral levels. Section 4 analyzes the driving factors of energy intensity differences among the G20 countries. Section 5 offers conclusions and policy implications.

\section{Model and Data Description}

\subsection{Energy Intensity in I-O Frameworks}

For environmentally extended I-O modeling, the imports assumption and I-O model selection are important components of empirical analysis. Since most embodiment studies use the Leontief I-O model [26-28] and the non-competitive imports assumption, which is more suitable for embodiment studies [29], we consider only the Leontief I-O model with non-competitive imports assumption.

I-O models can describe the relationship between final demand and energy consumption from the demand side. The basic single-area I-O model can be expressed by Equation (1):

$$
x=A x+y
$$

where $x$ is the vector of total output, $y$ is the vector of final demand, and $A$ is a direct consumption coefficient matrix that reflects the input amount of intermediate goods in each sector required for the production activities in that sector. Through a simple transformation, Equation (1) can be rewritten as a Leontief model:

$$
x=(\mathrm{I}-A)^{-1} y=B y
$$

where $B$ is the Leontief inverse matrix whose elements reflect the complete influence of a sector's unit production activities on the output of various sectors. In Equation (2), the total output is pulled by final demand through the Leontief inverse matrix. Correspondingly, the value added and energy consumption formation process of a region can also be examined from the same perspective, as shown in Equations (3) and (4). $E$ is defined as the total energy consumption of a country:

$$
\begin{gathered}
G D P=v=\hat{d} \cdot B \cdot y=1^{\prime} \cdot H \cdot y \\
E=f_{v}{ }^{\prime} \cdot v=f_{v}{ }^{\prime} \cdot H \cdot y
\end{gathered}
$$

where $v$ is the value added vector; $d$ is the vector of the value added coefficient, which is the value added created by unit production activities; $H=\hat{d} B$ is the value added requirement coefficient matrix, whose elements reflect the total pulling effect of the unit production activities of a sector on the value added of each sector; and $f_{v}$ is the sectoral energy intensity coefficient vector, which is the energy consumption generated by the value added by each sector.

The EEI is defined as the ratio of embodied energy to the embodied value added. According to [15], in the single-region I-O model, the energy intensity on the production side can be expressed as the EEI of the final demand. Thus, the energy intensity (energy consumption per unit of GDP) of a country can be expressed as the weighted sum of the EEI of each sector

$$
E E I=\frac{E}{G D P}=\frac{f_{v}{ }^{\prime} \cdot H \cdot y}{1^{\prime} \cdot H \cdot y}
$$


Industry weighted form:

$$
E E I=\sum_{j=1}^{n} w_{j} E E I_{j}
$$

where $j$ is the industry number and $w_{j}$ is the share of sector $j$ 's value added embodiment in the final consumption to the total value added.

\subsection{Multiplicative Decomposition of Aggregate Embodied Intensity}

According to [15], the decomposition result of the difference in EEI between the $m$-th G20 country and the group average $\mu$ of all G20 countries can be expressed as

$$
\begin{aligned}
& D_{\text {tot }}=\frac{E E I^{m}}{E E I^{\mu}}=\frac{\sum_{j=1}^{n} w_{j}^{m} E E I_{j}^{m}}{\sum_{j=1}^{n} w_{j}^{\mu} E E I_{j}^{\mu}}=\exp \left(\frac{\sum_{j=1}^{n} w_{j}^{m} E E I_{j}^{m}-\sum_{j=1}^{n} w_{j}^{\mu} E E I_{j}^{\mu}}{L\left(E E I^{m}, E E I^{\mu}\right)}\right) \\
& =\exp \left(\frac{\sum_{j=1}^{n}\left(w_{j}^{m} E E I_{j}^{m}-w_{j}^{\mu} E E I_{j}^{m}+w_{j}^{\mu} E E I_{j}^{m}-w_{j}^{\mu} E E I_{j}^{\mu}\right)}{L\left(E E I^{m}, E E I^{\mu}\right)}\right) \\
& =\exp \left(\frac{\sum_{j=1}^{n}\left(\left(w_{j}^{m}-w_{j}^{\mu}\right) E E I_{j}^{m}+w_{j}^{\mu}\left(E E I_{j}^{m}-E E I_{j}^{\mu}\right)\right)}{L\left(E E I^{m}, E E I^{\mu}\right)}\right) \\
& =\exp \left(\frac{\sum_{j=1}^{n}\left(L\left(w_{j}^{m}, w_{j}^{\mu}\right) \ln \left(\frac{w_{j}^{m}}{w_{j}^{\mu}}\right) E E I_{j}^{m}+w_{j}^{\mu} L\left(E E I^{m}, E E I^{\mu}\right) \ln \left(\frac{E E I^{m}}{E E I^{\mu}}\right)\right)}{L\left(E E I^{m}, E E I^{\mu}\right)}\right) \\
& =\prod_{j=1}^{n}\left(\frac{w_{j}^{m}}{w_{j}^{\mu}}\right)^{\frac{L\left(w_{j}^{m}, w_{j}^{\mu} w_{j}^{\mu}\right) E E I_{j}^{m}}{L\left(E E I^{m}, E E I^{\mu}\right)}}\left(\frac{E E I_{j}^{m}}{E E I_{j}^{\mu}}\right)^{\frac{w_{j}^{\mu} L\left(E E I_{j}^{m}, E E I_{j}^{\mu}\right)}{L\left(E E I^{m}, E E I^{\mu}\right)}}
\end{aligned}
$$

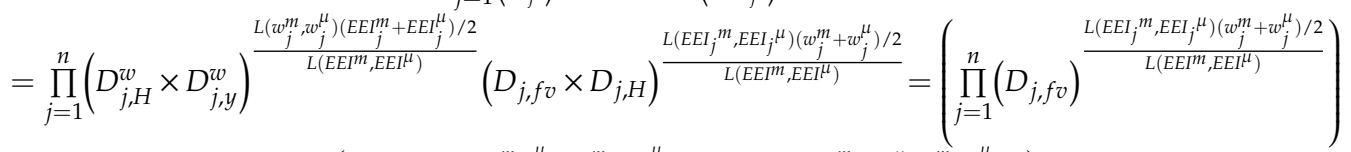

$$
\begin{aligned}
& \times\left(\prod_{j=1}^{n}\left(D_{j, H}^{w}\right) \frac{L\left(w_{j}^{m}, w_{j}^{\mu}\right)\left(E E I_{j}^{m}+E E I I_{j}^{\mu}\right) / 2}{L\left(E E I^{m}, E E I^{\mu}\right)}\left(D_{j, H}\right) \frac{L\left(E E I_{j}^{m}, E E j_{j}^{\mu}\right)\left(w_{j}^{m}+w_{j}^{\mu}\right) / 2}{L\left(E E I^{m}, E E I^{\mu}\right)}\right) \\
& \times\left(\prod_{j=1}^{n}\left(D_{j, y}^{w}\right)^{\frac{L\left(w_{j}^{m}, w_{j}^{\mu}\right)\left(E E I_{j}^{m}+E E I_{j}^{\mu}\right) / 2}{L\left(E E I^{m}, E E I^{\mu}\right.}}\right) \\
& =D_{f v} \times D_{H} \times D_{y}
\end{aligned}
$$

where $D_{f v}$ is the multiplicative sectoral energy intensity effect, $D_{H}$ is the multiplicative input structure effect, and $D_{y}$ is the multiplicative final demand structure effect.

In Equation (7), the ratio of the EEI of the $j$-th sector in the $m$-th G20 country to the average EEI of the corresponding sector group can be expressed as:

$$
\begin{aligned}
& D_{j}=\frac{E E I_{j}^{m}}{E E I_{j}^{\mu}}=\frac{f_{v}^{m \prime} H^{m} \mathrm{y}_{j} / 1^{\prime} H^{m} y_{j}}{f_{v}^{\mu \prime} H^{\mu} y_{j} / 1^{\prime} H^{\mu} y_{j}} \\
& =\frac{f_{v}^{m \prime} H^{m} 1_{j} / 1^{\prime} H^{m} 1_{j}}{f_{v}^{\mu \prime} H^{\mu} 1_{j} / 1^{\prime} H^{\mu} 1_{j}}=\left(\frac{f_{v}^{m \prime} H^{m} 1_{j}}{f_{v}^{\mu} H^{\mu} 1_{j}}\right) /\left(\frac{1^{\prime} H^{m} 1_{j}}{1^{\prime} H^{\mu} 1_{j}}\right) \\
& =\left(\frac{f_{v}^{m \prime} H^{m} 1_{j}}{f_{v}^{m \prime} H^{\mu} 1_{j}} \times \frac{f_{v}^{m \prime} H^{\mu} 1_{j}}{f_{v}^{\mu \prime} H^{\mu} 1_{j}}\right) /\left(\frac{1^{\prime} H^{m} 1_{j}}{1^{\prime} H^{\mu} 1_{j}}\right) \\
& =\left(\frac{f_{v}^{\mu \prime} H^{m} 1_{j}}{f_{v}^{\mu^{\prime}} H^{\mu} 1_{j}} \times \frac{f_{v}^{m \prime} H^{m} 1_{j}}{f_{v}^{\mu^{\prime}} H^{m} 1_{j}}\right) /\left(\frac{1^{\prime} H^{m} 1_{j}}{1^{\prime} H^{\mu} 1_{j}}\right)
\end{aligned}
$$

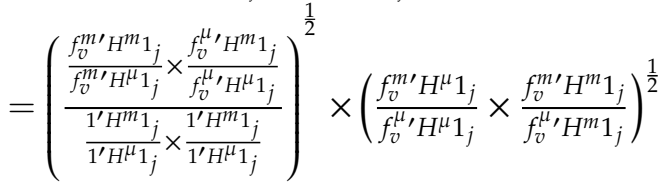

$$
\begin{aligned}
& =D_{j, H} \times D_{j, f v}
\end{aligned}
$$


In Equation (7), the ratio of the GDP of the $m$-th G20 country to the average GDP of the group can be expressed as

$$
\begin{aligned}
& D_{j}^{w}=\frac{w_{j}^{m}}{w_{j}^{\mu}}=\frac{1^{\prime} H^{m} y_{j}^{m} / 1^{\prime} H^{m} y^{m}}{1^{\prime} H^{\mu} y_{j}^{\mu} / 1^{\prime} H^{\mu} y^{m}}=\left(\frac{1^{\prime} H^{m} y_{j}^{m}}{1^{\prime} H^{\mu} y_{j}^{\mu}}\right) /\left(\frac{1^{\prime} H^{m} y^{m}}{1^{\prime} H^{\mu} y^{m}}\right) \\
& =\left(\frac{1^{\prime} H^{m} y_{j}^{m}}{1^{\prime} H^{m} y_{j}^{\mu}} \times \frac{1^{\prime} H^{m} y_{j}^{\mu}}{1^{\prime} H^{\mu} y_{j}^{\mu}}\right) /\left(\frac{1^{\prime} H^{m} y^{m}}{1^{\prime} H^{m} y^{\mu}} \times \frac{1^{\prime} H^{m} y^{\mu}}{1^{\prime} H^{\mu} y^{\mu}}\right) \\
& =\left(\frac{1^{\prime} H^{\mu} y_{j}^{m}}{1^{\prime} H^{\mu} y_{j}^{\mu}} \times \frac{1^{\prime} H^{m} y_{j}^{m}}{1^{\prime} H^{\mu} y_{j}^{m}}\right) /\left(\frac{1^{\prime} H^{\mu} y^{m}}{1^{\prime} H^{\mu} y^{\mu}} \times \frac{1^{\prime} H^{m} y^{\mu}}{1^{\prime} H^{\mu} y^{\mu}}\right) \\
& =\left(\frac{\frac{1^{\prime} H^{m} y_{j}^{m}}{1^{\prime} H^{m} y_{j}^{\mu}} \times \frac{1^{\prime} H^{\mu} y_{j}^{m}}{1^{\prime} H^{\mu} y_{j}^{\mu}}}{\frac{1^{\prime} H^{m} y^{m}}{1^{\prime} H^{m} y^{\mu}} \times \frac{1^{\prime} H^{\mu} y^{m}}{1^{\prime} H^{\mu} y^{\mu}}}\right)^{\frac{1}{2}} \times\left(\frac{\frac{1^{\prime} H^{m} y_{j}^{\mu}}{1^{\prime} H^{\mu} y_{j}^{\mu}} \times \frac{1^{\prime} H^{m} y_{j}^{m}}{1^{\prime} H^{\mu} y_{j}^{m}}}{\frac{1^{\prime} H^{m} y^{\mu}}{1^{\prime} H^{\mu} y^{\mu}} \times \frac{1^{\prime} H^{m} y^{m}}{1^{\prime} H^{\mu} y^{m}}}\right)^{\frac{1}{2}} \\
& =D_{j, y}^{w} \times D_{j, H}^{w}
\end{aligned}
$$

\subsection{Data}

This study uses the World Input-Output Tables released by the World Input-Output Database (WIOD) [30]. The database provides tables from 2000 to 2014 covering 56 sectors and 44 countries and regions (Table A1 of Appendix A describes the correspondence between the 56 sector classifications in the WIOD and the ISIC Rev4 sector classification). The energy data are collected from the August 2019 edition of the WIOD environmental account, which provides the amounts of gross energy use of 12 energy commodities for 56 sectors and households (Table A2 describes the 12 energy product types). We select 22 key sectors (Table A3) for the G20 countries whose embodied energy consumption exceeded $80 \%$ of the total sector in 2014 and analyze them from the demand side.

The data provided by the WIOD does not include Argentina, South Africa, Saudi Arabia, and the European Union, so this study mainly analyzes 16 G20 countries: five European countries, namely, Germany, France, British, Italy, and Turkey; Australia; three North American countries, that is, the United States, Mexico, Canada; Brazil in South America; five Asian countries, Japan, South Korea, Indonesia, India, China; and Russia. In addition, some sectors register zero output, value added, and final demand in the I-O tables (see Table A4 for details); we assign them a value of $10^{-20}$ to avoid singular values according to [31,32].

\section{Differences in Energy Intensity and Sector Structure among the G20 Countries}

The total energy consumption of the G20 countries increased from 2000 to 2014. Figure 1 shows that China and the United States consume significantly more energy than other G20 countries. In 2014, the average energy consumption of the G20 countries was 73 EJ. The energy consumption of China, the United States, Russia, and India is higher than the average value of all G20 countries at 342 EJ, 275 EJ, $100 \mathrm{EJ}$, and $90 \mathrm{EJ}$, respectively. Thus, reducing the total energy consumption of these four countries has great potential to reduce global energy consumption and improve energy efficiency.

The gap in aggregate energy intensity among the G20 countries tended to converge from 2000 to 2014. Reducing energy intensity in Russia, India, China, and South Korea has great potential to reduce global energy consumption and improve energy efficiency. Each point in Figure 2 represents the ratio of the energy intensity of each G20 country in 2000-2014 to the average energy intensity of the G20 countries in the corresponding year. The average energy intensity of the G20 countries in 2000, 2005, 2010, and 2014 is 15.98 EJ per million dollars, 13.27 EJ per million dollars, 10.85 EJ per million dollars, and 9.81 EJ per million dollars, respectively. 


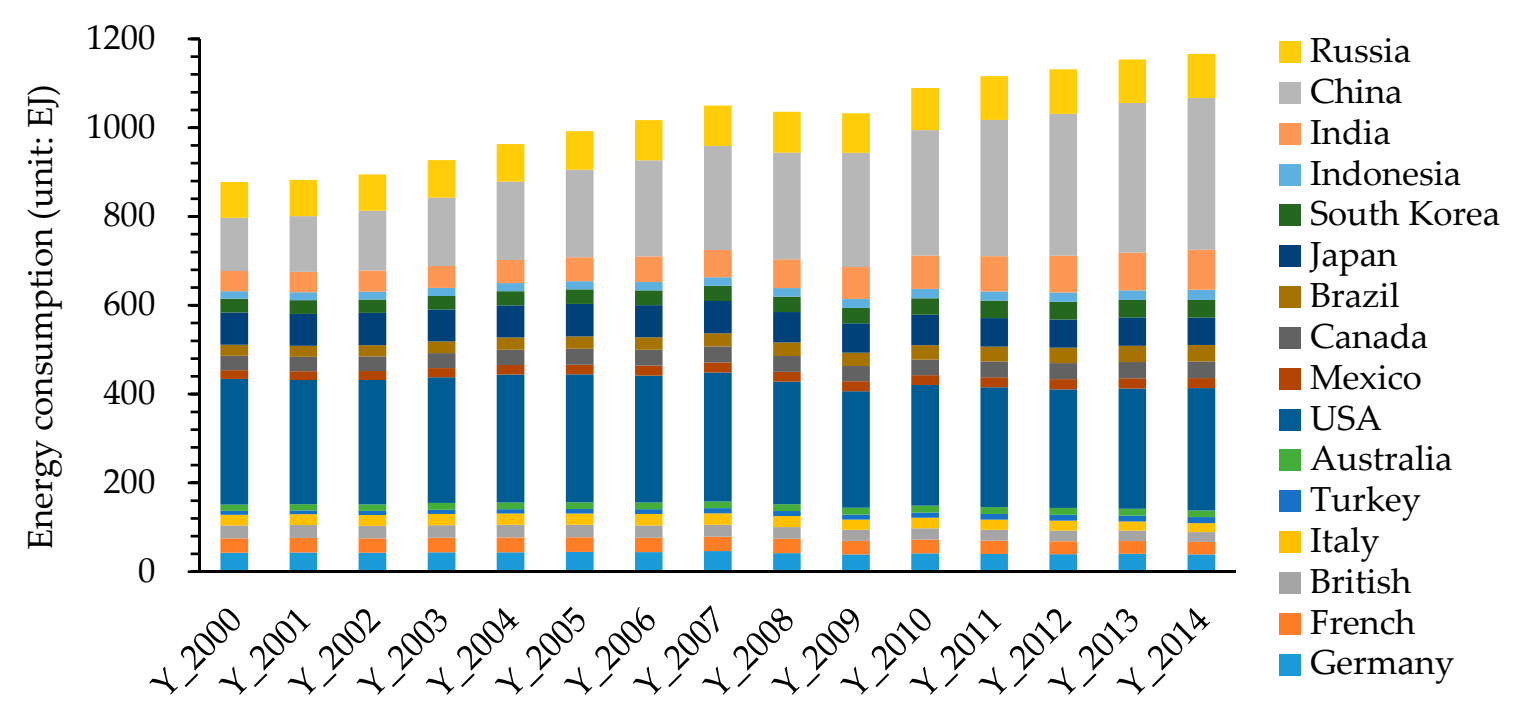

Figure 1. Energy consumption of Group of Twenty (G20) countries from 2000 to 2014.

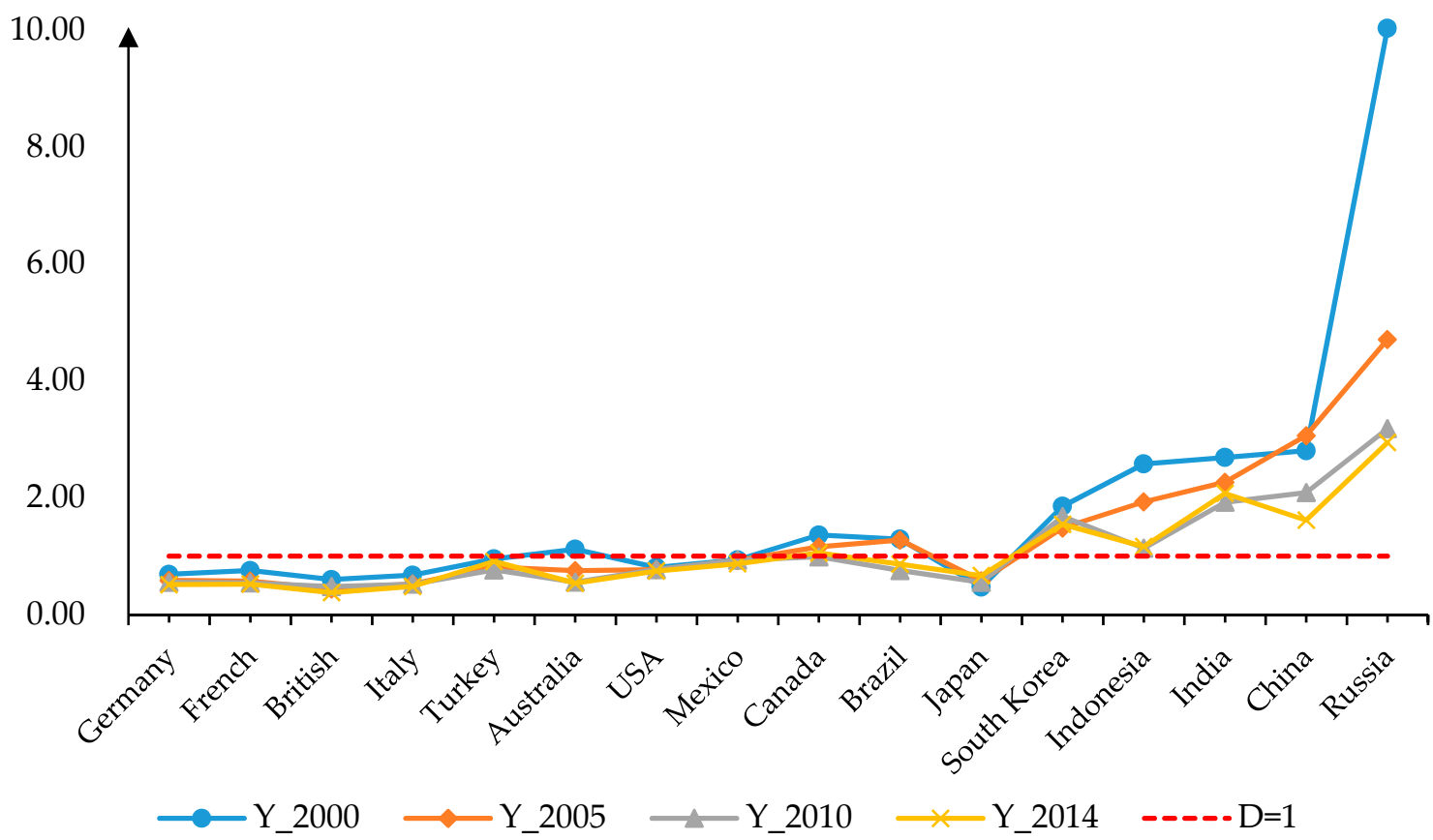

Figure 2. Ratio of G20 countries and groups average energy intensity.

The average energy efficiency of the G20 countries increased yearly from 2000 to 2014 . At the same time, the gap between the energy intensity of each G20 country and the average energy intensity of the G20 countries tended to converge from 2000 to 2014. The largest convergence was observed for the gap between the energy intensity of Russia and the average level. Despite a converging trend, the energy intensity of Russia, India, China, South Korea, Indonesia, and Canada in 2014 was still higher than the average level of the G20 countries. In 2014, the highest energy intensity was Russia's, which registered a value 2.94 times the average level of the G20 countries, followed by those of India (2.07 times), China (1.62 times), and South Korea (1.54 times). It should be noted that developed countries such as the United States and those in European countries have higher energy efficiencies, while post-industrial countries such as Russia, China, India, and South Korea have lower energy efficiencies.

According to Figures 1 and 2, the optimization of energy efficiency in Russia, India, China, and South Korea has great potential for global energy consumption reduction and energy efficiency 
improvement. As can be seen from Figure 1, the energy consumption of the United States is much higher than that of other developed countries, but its energy intensity in Figure 2 is much lower than the average level of the G20 countries. This indicates that the United States, being the world leader in technology, has a much higher energy efficiency than other G20 countries. However, although it consumes a large amount of energy every year, it has shifted some production activities characterized by high energy consumption, high pollution, and low economic efficiency to other export-oriented countries, thus reducing its energy intensity.

Each point in Figure 3 represents the ratio of the EEI of key sectors to the average level of corresponding sectors. In 2014, for example, most of the key industries in Russia, China, India, and South Korea had a higher energy consumption intensity than the average levels of their corresponding industries.

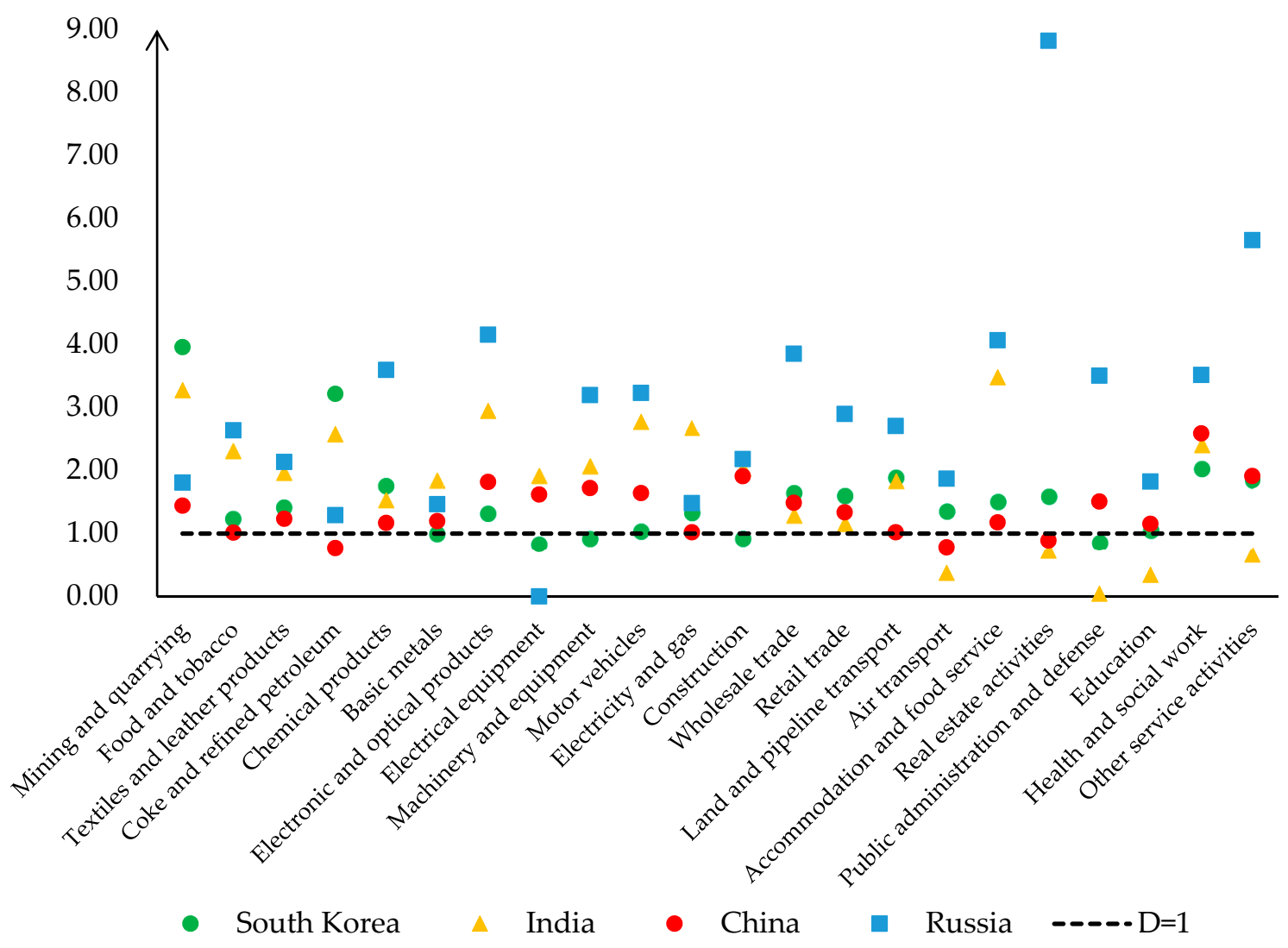

Figure 3. The ratio of the embodied energy intensity (EEI) of key sectors in high energy intensity countries to the average level of corresponding sectors in G20 countries in 2014.

For India and China, which have similar development patterns and levels, the EEI of mining and quarrying, food and tobacco, textiles and leather products, chemical products, basic metals, electronic and optical products, electrical equipment, machinery and equipment, motor vehicles, electricity and gas, construction, wholesale trade, retail trade, land and pipeline transport, accommodation and food service, and health and social work are higher than the average levels of the G20 countries. In addition, the EEI of India's coke and refined petroleum and China's other service activities, education, and public administration and defense are also higher than the averages. In 2014, India's energy intensity was 2.08 times the average level of the G20 countries. From Figure 3, it can be seen that the EEI of these key sectors in India were much higher than the average level of their counterparts in the G20 countries. Among them, accommodation and food service and mining and quarrying had the greatest impact, at 3.48 and 3.27 times the average level, respectively. Meanwhile, China's energy intensity in 2014 was 1.60 times the average level of the G20 countries. As seen in Figure 3, although most key 
sectors in China have a higher energy intensity than average levels, no sector exhibits abnormally high energy intensity.

The EEI of Russia in 2014 was 2.99 times the average level of the G20 countries. The 10 sectors that had the greatest impacts on Russia's high energy intensity were real estate activities, other service activities, electronic and optical products, accommodation and food service, wholesale trade, chemical products, health and social work, public administration and defense, motor vehicles, and machinery and equipment. The energy intensities of these sectors were 8.82, 5.66, 4.16, 4.07, 3.85, 3.60, 3.52, 3.50, 3.23 , and 3.20 times the average levels, respectively.

In 2014, South Korea's energy intensity was 1.61 times the average level. The EEI of 18 key industries in South Korea were above the average level, except electrical equipment, machinery and equipment, construction, and public administration and defense. The two sectors with the greatest impact were mining and quarrying and coal and refined petroleum, whose values were 3.96 and 3.22 times the average of the G20 countries, respectively.

\section{Driving Factors of Spatial Differences in EEI}

\subsection{National Level}

Significant differences in energy intensity are observed for 2014 among the G20 countries. We use multiplicative SDA to analyze the driving factors of energy intensity in low-energy-intensity countries such as Australia and European countries that are G20 countries. The input structure effect is the most important factor and causes the energy intensity of low-energy-intensity countries to be lower than the average level of the G20 countries, followed by the sectoral energy intensity effect. For the same phenomenon in European countries, Australia, Brazil, and Mexico, the input structure effect is the most important factor, as shown in Table 1. This indicates that these countries undertake a cleaner division of labor in the production division network. The input structure effects of Italy, France, Germany, the British, Turkey, Brazil, and Mexico are 0.33, 0.40, 0.51, 0.56, 0.84, 0.84, and 0.90, respectively. This implies that other influencing factors remain the same. The contribution rates of the input structure effect to these low-energy-intensity countries are below average: $67 \%, 60 \%, 49 \%, 44 \%, 16 \%, 16 \%$, and $10 \%$, respectively. For the United States and Japan, the sectoral energy intensity effect is the main factor that causes their energy intensity to be lower than the average level, which indicates that their energy efficiency is higher than that of other G20 countries. With other influencing factors remaining the same, the contributions of the sectoral energy intensity effect in these two countries are $15 \%$ and $21 \%$, respectively.

As above, we use the multiplicative SDA to analyze the driving factors of energy intensity in high-energy-intensity G20 countries. The results indicate multiple reasons for the energy intensity of each country being higher than the average.

The differences in sectoral energy intensity effect indicates large differences in energy utilization technologies between countries. The impacts of the sectoral energy intensity effect on energy intensity depend on the differences between each country's energy use efficiency and the average energy use efficiency of the G20 countries. The sectoral energy intensity effect is the main factor that causes the energy intensity of the five highest-energy-intensity countries, except Indonesia, to be higher than the average level. This is true especially for India, South Korea, and Canada. This means that these three countries still have a large gap in energy efficiency compared with other G20 countries. As shown in Table 1, with other factors constant, the contribution rates of the sectoral energy intensity effect to the above-average energy intensity of India, South Korea, and Canada are $16 \%, 50 \%$, and $113 \%$, respectively. The case of Indonesia is unique: when the other influencing factors remain the same, the sectoral energy intensity effect causes Indonesia's energy intensity to be lower than the average, and its contribution rate is $19 \%$. 
Table 1. Multiplicative structural decomposition analysis (SDA) of EEI differences in G20 countries in 2014.

\begin{tabular}{ccccc}
\hline Country & $\boldsymbol{D}_{\boldsymbol{t o t}}$ & $\boldsymbol{D}_{\boldsymbol{f v}}$ & $\boldsymbol{D}_{\boldsymbol{H}}$ & $\boldsymbol{D}_{\boldsymbol{y}}$ \\
\hline Germany & 0.51 & 0.87 & 0.51 & 1.17 \\
French & 0.52 & 1.39 & 0.40 & 0.95 \\
British & 0.38 & 0.79 & 0.56 & 0.85 \\
Italy & 0.48 & 1.49 & 0.33 & 0.98 \\
Turkey & 0.92 & 0.99 & 0.84 & 1.11 \\
Australia & 0.55 & 0.81 & 0.77 & 0.88 \\
USA & 0.75 & 0.85 & 1.00 & 0.87 \\
Mexico & 0.88 & 0.92 & 0.90 & 1.07 \\
Canada & 1.06 & 1.16 & 0.87 & 1.04 \\
Brazil & 0.87 & 1.00 & 0.84 & 1.03 \\
Japan & 0.67 & 0.79 & 0.91 & 0.93 \\
South Korea & 1.61 & 1.5 & 0.80 & 1.34 \\
Indonesia & 1.17 & 0.81 & 1.14 & 1.27 \\
India & 2.08 & 2.13 & 0.79 & 1.24 \\
China & 1.62 & 1.16 & 1.26 & 1.11 \\
Russia & 2.99 & 1.55 & 1.63 & 1.19 \\
\hline
\end{tabular}

The input structure effect reflects differences in energy intensity between countries due to differences in the division of intermediate goods. If a country undertook cleaner divisions of production in the G20 production division network in 2014, with other factors constant, the input structure effect caused the country's energy intensity to be lower than the G20 average. If it undertook the task of non-clean divisions of production, the country's energy intensity was driven higher than the G20 average. The input structure effect is the main factor that caused the energy intensity of Russia, China, and Indonesia to be higher than the average. This is true especially for Russia and China. As shown in Table 1, with other factors constant, the input structure effect contributes to the above-average energy intensity of Russia and China by $20 \%$ and $63 \%$, respectively.

The impact of the final demand structure effect on the energy intensity depends on shifts in the demand structure. If changes in the demand structure lead to larger demand for energy-intensive products in a country, it will drive the country's energy intensity higher than the G20 average. However, if such changes lead to larger demand for non-energy-intensive products, it will cause the energy intensity to be lower. The final demand structure effect drives the energy intensity of high-energy-intensity countries higher than the average level. This is true especially for Indonesia, where the final demand structure effect is the most important factor causing the energy intensity to be higher than the average. As shown in Table 1, with other factors constant, the final demand structure effect contributes $27 \%$ in Indonesia.

\subsection{Theoretical Optimization of EEI}

According to Equation (7), the total embodied energy consumption of a country is given by $E E^{m}=E E I^{m} \cdot G D P^{m}=E E I^{\mu} \cdot D_{f v}^{m} \cdot D_{H}^{m} \cdot D_{y}^{m} \cdot G D P^{m}$. Taking the average of the G20 countries as a reference, the theoretical optimization of their energy intensity means that the sectoral energy intensity effect, input structure effect, and final demand structure effect are optimized to the average level of the G20 countries. Table 2 shows the embodied energy consumption saved by six countries whose EEI (Table 1) is higher than the average level of the G20 countries after theoretical optimization.

In theory, reducing the energy intensity sufficiently fast could offset natural increases in energy consumption due to population and economic growth and could even lead to a decline in the total energy demand. According to our calculations, the total embodied energy consumption of China, Russia, India, South Korea, Indonesia, and Canada in 2014 was 162.90, 46.71, 40.51, 19.49, 9.92, and 17.33 EJ, respectively. Therefore, after the theoretical optimization of the EEI of these six countries, their embodied energy consumption will be reduced by $38.52 \%, 68.38 \%, 52.43 \%, 39.35 \%, 14.82 \%$, and $4.67 \%$, 
respectively. In 2014, the total embodied energy consumption of the G20 countries was 578.09 EJ. The embodied energy consumption decline in these six countries was equivalent to $21.78 \%$ of the G20's total energy consumption. Thus, reducing the energy intensity of the G20 countries, especially that of China, Russia, India, and South Korea, has great potential to reduce the global energy consumption.

Table 2. Theoretical optimization quantity of embodied energy consumption (EJ).

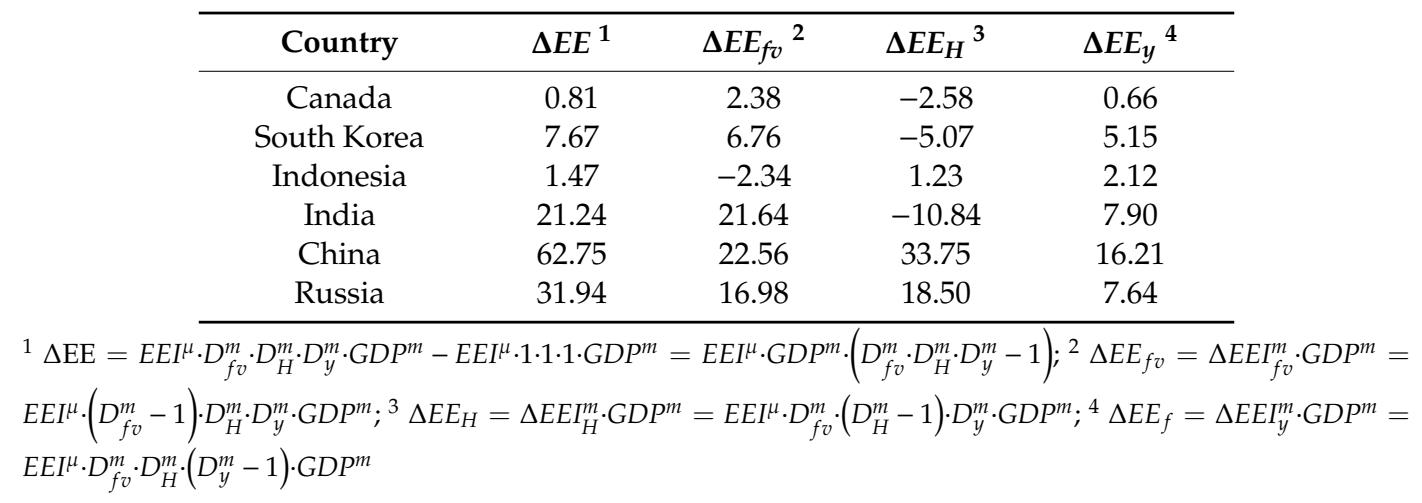

\subsection{Sectoral Level}

Based on Equation (8), this section uses the multiplicative SDA method to decompose the changes in the EEI of the key sectors of the high-energy-intensity G20 countries (Tables 3-6). These driving factors include the sectoral energy intensity and input structure effects. According to Equation (4), from the perspective of the demand side, the formation process of energy consumption in an area can be understood as the pulling influence of the final demand through the energy consumption intensity coefficient matrix and complete value added coefficient matrix. Therefore, key industries that determine the energy intensity of the whole country have a high proportion of final demand and a high EEI.

Table 3. Multiplicative SDA of EEI difference of key sectors in Russia in 2014.

\begin{tabular}{|c|c|c|c|c|}
\hline \multirow{2}{*}{ Short Description } & \multicolumn{4}{|c|}{ Russia } \\
\hline & $D_{j}$ & $D_{j, f v}$ & $D_{j, H}$ & $y_{j}(\%)$ \\
\hline Real estate activities & 8.81 & 2.19 & 4.02 & 3.89 \\
\hline Wholesale trade & 3.85 & 1.51 & 2.54 & 9.5 \\
\hline Health and social work & 3.51 & 1.7 & 2.07 & 5.94 \\
\hline Public administration and defense & 3.5 & 1.5 & 2.33 & 7.66 \\
\hline Retail trade & 2.9 & 1.53 & 1.89 & 4.04 \\
\hline Land and pipeline transport & 2.71 & 1.61 & 1.68 & 4.56 \\
\hline Food and tobacco & 2.64 & 1.67 & 1.58 & 5.38 \\
\hline Construction & 2.18 & 1.49 & 1.46 & 11.64 \\
\hline Education & 1.82 & 1.17 & 1.55 & 3.93 \\
\hline Mining and quarrying & 1.81 & 1.49 & 1.21 & 10.02 \\
\hline Coke and refined petroleum & 1.29 & 0.9 & 1.43 & 3 \\
\hline Other service activities & 5.65 & 1.92 & 2.95 & 1.6 \\
\hline Electronic and optical products & 4.15 & 1.83 & 2.27 & 0.73 \\
\hline Accommodation and food service & 4.06 & 1.73 & 2.34 & 1.08 \\
\hline Chemical products & 3.6 & 3.02 & 1.19 & 1.72 \\
\hline Motor vehicles & 3.23 & 1.85 & 1.75 & 2.14 \\
\hline Machinery and equipment & 3.2 & 1.74 & 1.83 & 1.75 \\
\hline Textiles and leather products & 2.13 & 1.78 & 1.2 & 0.56 \\
\hline Air transport & 1.87 & 1.27 & 1.48 & 0.49 \\
\hline Electricity and gas & 1.48 & 1.85 & 0.8 & 1.06 \\
\hline Basic metals & 1.46 & 1.3 & 1.12 & 2.35 \\
\hline Electrical equipment & 0 & 0 & 0 & 0 \\
\hline $\begin{array}{l}\text { The percentage of } y_{j} \text { of key industries } \\
\text { in total industry }\end{array}$ & & & & 83.06 \\
\hline
\end{tabular}


Table 4. Multiplicative SDA of EEI difference of key sectors in China in 2014.

\begin{tabular}{ccccc}
\hline Short Description & \multicolumn{4}{c}{ China } \\
\cline { 2 - 5 } & $\boldsymbol{D}_{\boldsymbol{j}}$ & $\boldsymbol{D}_{j, f v}$ & $\boldsymbol{D}_{\boldsymbol{j}, \boldsymbol{H}}$ & $\boldsymbol{y}_{\boldsymbol{j}} \mathbf{( \% )}$ \\
\hline Health and social work & 2.59 & 1.46 & 1.77 & 4.41 \\
Construction & 1.91 & 1.18 & 1.61 & 23.7 \\
Electronic and optical products & 1.82 & 1.21 & 1.5 & 5.49 \\
Machinery and equipment & 1.72 & 1.22 & 1.41 & 4.66 \\
Motor vehicles & 1.64 & 1.21 & 1.36 & 4.57 \\
Electrical equipment & 1.62 & 1.23 & 1.32 & 3.3 \\
Public administration and defense & 1.51 & 1.19 & 1.26 & 6.09 \\
Wholesale trade & 1.49 & 1.19 & 1.25 & 3.84 \\
Textiles and leather products & 1.23 & 1.14 & 1.09 & 4.08 \\
Education & 1.15 & 0.9 & 1.28 & 4.55 \\
Other service activities & 1.91 & 1.35 & 1.41 & 2 \\
Mining and quarrying & 1.44 & 1.09 & 1.32 & 0.23 \\
Retail trade & 1.34 & 1.12 & 1.2 & 0.79 \\
Basic metals & 1.2 & 1.24 & 0.96 & 0.86 \\
Chemical products & 1.18 & 1.05 & 1.12 & 2.03 \\
Electricity and gas & 1.17 & 1.16 & 1.01 & 1.06 \\
Accommodation and food service & 1.02 & 1.37 & 0.74 & 0.56 \\
Land and pipeline transport & 1.02 & 0.95 & 1.07 & 1.06 \\
Food and tobacco & 1.01 & 1.01 & 1 & 6.12 \\
Real estate activities & 0.89 & 1.2 & 0.74 & 4.03 \\
Air transport & 0.78 & 0.72 & 1.09 & 0.23 \\
Coke and refined petroleum & 0.77 & 1 & 0.77 & 0.57 \\
\hline The percentage of $y_{j}$ of key industries & & & & 84.25 \\
in total industry & & & & \\
\hline
\end{tabular}

Table 5. Multiplicative SDA of EEI difference of key sectors in India in 2014.

\begin{tabular}{|c|c|c|c|c|}
\hline \multirow{2}{*}{ Short Description } & \multicolumn{4}{|c|}{ India } \\
\hline & $D_{j}$ & $D_{j, f v}$ & $D_{j, H}$ & $y_{j}(\%)$ \\
\hline Motor vehicles & 2.77 & 2.3 & 1.21 & 3.1 \\
\hline Coke and refined petroleum & 2.58 & 2.09 & 1.24 & 3.63 \\
\hline Food and tobacco & 2.31 & 2.89 & 0.8 & 6.23 \\
\hline Construction & 2.03 & 2.37 & 0.86 & 12.68 \\
\hline Textiles and leather products & 1.97 & 2.12 & 0.93 & 4.63 \\
\hline Land and pipeline transport & 1.84 & 1.81 & 1.02 & 6.22 \\
\hline Wholesale trade & 1.3 & 1.99 & 0.65 & 3.01 \\
\hline Retail trade & 1.17 & 1.78 & 0.65 & 4.91 \\
\hline Accommodation and food service & 3.47 & 3.79 & 0.92 & 2.15 \\
\hline Mining and quarrying & 3.27 & 3.8 & 0.86 & 0.33 \\
\hline Electronic and optical products & 2.94 & 2.32 & 1.27 & 0.59 \\
\hline Electricity and gas & 2.68 & 2.4 & 1.12 & 0.52 \\
\hline Health and social work & 2.4 & 1.91 & 1.26 & 1.92 \\
\hline Machinery and equipment & 2.07 & 2.23 & 0.93 & 1.69 \\
\hline Electrical equipment & 1.92 & 2.23 & 0.86 & 1.06 \\
\hline Basic metals & 1.85 & 2.25 & 0.82 & 2.26 \\
\hline Chemical products & 1.54 & 1.88 & 0.82 & 1.77 \\
\hline Real estate activities & 0.73 & 2.17 & 0.33 & 5.72 \\
\hline Other service activities & 0.67 & 1.5 & 0.44 & 1.89 \\
\hline Air transport & 0.38 & 0.63 & 0.6 & 0.2 \\
\hline Education & 0.34 & 0.74 & 0.47 & 3.75 \\
\hline Public administration and defense & 0.04 & 0.51 & 0.09 & 5.85 \\
\hline $\begin{array}{c}\text { The percentage of } y_{j} \text { of key industries } \\
\text { in total industry }\end{array}$ & & & & 74.13 \\
\hline
\end{tabular}


Table 6. Multiplicative SDA of EEI difference of key sectors in South Korea in 2014.

\begin{tabular}{|c|c|c|c|c|}
\hline \multirow{2}{*}{ Short Description } & \multicolumn{4}{|c|}{ South Korea } \\
\hline & $D_{j}$ & $D_{j, f v}$ & $D_{j, H}$ & $y_{j}(\%)$ \\
\hline Coke and refined petroleum & 3.22 & 2.44 & 1.32 & 3.34 \\
\hline Health and social work & 2.03 & 1.49 & 1.36 & 5.36 \\
\hline Chemical products & 1.76 & 1.6 & 1.1 & 3.76 \\
\hline Real estate activities & 1.59 & 1.5 & 1.06 & 5.19 \\
\hline Electronic and optical products & 1.33 & 1.39 & 0.95 & 11.1 \\
\hline Mining and quarrying & 3.96 & 4.34 & 0.91 & -0.03 \\
\hline Land and pipeline transport & 1.89 & 1.96 & 0.96 & 1.26 \\
\hline Other service activities & 1.85 & 1.43 & 1.29 & 2.76 \\
\hline Wholesale trade & 1.65 & 1.57 & 1.05 & 2.07 \\
\hline Retail trade & 1.6 & 1.43 & 1.12 & 2.68 \\
\hline Accommodation and food service & 1.51 & 1.41 & 1.07 & 2.32 \\
\hline Textiles and leather products & 1.42 & 1.29 & 1.1 & 2.16 \\
\hline Air transport & 1.36 & 1.59 & 0.85 & 0.54 \\
\hline Electricity and gas & 1.34 & 1.13 & 1.19 & 1.15 \\
\hline Food and tobacco & 1.24 & 1.34 & 0.93 & 2.64 \\
\hline Education & 1.06 & 0.93 & 1.13 & 5.23 \\
\hline Motor vehicles & 1.04 & 1.27 & 0.82 & 5.46 \\
\hline Basic metals & 1 & 1.01 & 1 & 2.01 \\
\hline Construction & 0.93 & 1.31 & 0.71 & 9.92 \\
\hline Machinery and equipment & 0.92 & 1.17 & 0.79 & 3.53 \\
\hline Public administration and defense & 0.86 & 1.32 & 0.65 & 7.14 \\
\hline Electrical equipment & 0.84 & 1.22 & 0.68 & 1.86 \\
\hline $\begin{array}{l}\text { The percentage of } y_{j} \text { of key industries } \\
\text { in total industry }\end{array}$ & & & & 81.46 \\
\hline
\end{tabular}

Russia's energy consumption is largely determined by other services, wholesale and retail, transport, food and tobacco, construction, heavy manufacturing. The input structure effect is the most important factor that causes the EEI of these industries to be higher than the average levels of the corresponding industries of the G20 countries, especially for food and tobacco, wholesale trade, retail trade, land and pipeline transport, real estate activities, public administration and defense, education, and health and social work. The sectoral energy intensity effect also contributes greatly to Russia's high energy intensity, especially for food and tobacco, wholesale trade, retail trade, land and pipeline transport, real estate activities, public administration and defense, and health and social work.

As a manufacturing country, China's energy consumption is mainly determined by other services, construction, heavy manufacturing, light manufacturing, wholesale trade, textiles and leather products, according to Table 4 . The input structure effect is the most important factor that causes the EEI of these industries to be higher than the average level of the corresponding industries of the G20 countries, especially for electronic and optical products, construction, and health and social work. This indicates that these industries in China undertook non-clean divisions of production in the production division network of the G20 countries in 2014.

India's energy consumption is mainly determined by these eight industries according to Table 5 . The sectoral energy intensity effect is the most important factor that causes the EEI of these industries to be higher than the average levels of the corresponding industries in the G20 countries, especially for food and tobacco, textiles and leather products, coal and refined petroleum, motor vehicles, and construction. This shows that there is still a big gap between these industries and other G20 countries in terms of energy efficiency.

South Korea's energy consumption is largely determined by heavy manufacturing and other services according to Table 6 . The sectoral energy intensity effect is the most important factor that causes the EEI of these industries to be higher than the average level of the corresponding industries 
in the G20 countries. This is true especially for the traditionally heavy industries of coal and refined petroleum and chemical products.

\section{Discussion and Conclusions}

This study analyzes the spatial differences in energy intensity between the G20 countries from both aggregate and sectoral levels. A country's energy intensity can be expressed as a weighted sum of the EEI of each sector. Multiplicative SDA was used to further analyze the driving factors of spatial differences in energy intensity at the aggregate and sectoral levels. The impact of the input structure effect on the EEI of key sectors differs between these countries. The results indicate the following.

(1) The gap in aggregate energy intensity among the G20 countries tended to converge from 2000 to 2014. At the regional level, the energy consumption intensity of the G20 countries varies greatly from region to region. Developed countries such as the United States and those in European countries have higher energy efficiency, while post-industrial countries such as Russia, China, and India have lower energy efficiency. Reducing energy intensity in Russia, India, China, and South Korea has great potential to reduce global energy consumption and improve global energy efficiency. In 2014, the EEI of 21 key industries in Russia, 17 in India, 19 in China, and 18 in South Korea were higher than the average level of the corresponding industries' average of the G20 countries.

(2) With other factors remaining the same, the sectoral energy intensity effect leads to above-average energy intensity levels in the five highest-energy-intensity countries except Indonesia. In Russia, China, and Indonesia, the above-average energy intensity levels are caused by the input structure effect. Furthermore, the final demand structure effect causes the energy intensity of high-energy-consuming countries to be higher than the G20 average. The main driving force for the above-average energy intensity in India, South Korea, and Canada is the sectoral energy intensity effect, in Russia and China it is the input structure effect, and in Indonesia it is the final demand structure effect.

(3) Taking the average of the G20 countries as a reference, after the theoretical optimization of the sectoral energy intensity effect, input structure effect, and final demand structure effect of six high-energy-intensity countries, the embodied energy consumption of these countries decreases. Among them, China, Russia, and India will reduce their embodied energy consumption by $62.75 \mathrm{EJ}$, 31.94 EJ and 21.24 EJ, respectively. The EEI decline in six high-energy-intensity countries is equivalent to $21.78 \%$ of the G20's total energy consumption in 2014 . Thus, reducing the energy intensity of the G20 countries, especially China, Russia, and India, has great potential for reducing the global energy consumption.

(4) The EEI drivers of national key industries with high energy consumption intensity in the G20 countries were decomposed into the sectoral energy intensity effect and input structure effect. The sectoral energy intensity effect is the most important factor that leads to the EEI of key industries in India and South Korea being higher than the average levels of the corresponding industries in the G20 countries. For Russia and China, the input structure effect is the most important factor.

Given the above conclusions, we offer the following suggestions.

(1) The reduction in energy intensity of the G20 countries should focus not only on production-side management, but also on demand-side governance. It should trace all indirect industrial links behind the direct links and fully depict the driving effects of final demand on each industry's energy consumption. When these countries participate in the international division of labor, it would be beneficial for them to shift production to value chains with relatively low energy consumption and relatively high added value. This shift will help reduce the energy intensity of these countries.

(2) The G20 countries should optimize each country's aggregate final demand structure and intermediate input structure as well as improve energy efficiency. The G20 countries with high energy intensity should continue to optimize the final demand structure so that changes in the demand structure can lead to greater demand for non-energy-intensive products. Russia, China, and Indonesia should continue to optimize the input structure of intermediate products. These countries should undertake cleaner production tasks as much as possible in their production division networks. Russia, 
India, China, South Korea, and Canada should actively learn from developed countries in Europe as well as Australia to improve energy efficiency.

(3) It is important to improve energy efficiency in key industries and optimize the structure of their intermediate inputs. In particular, the optimization of the energy efficiency of key industries in India and South Korea and the intermediate product input structure in Russia and China will contribute positively to the reduction in global energy consumption. There should be greater focus on improving the energy efficiency of food and tobacco, textiles and leather products, coal and refined petroleum, motor vehicles, and construction in India, and coal and refined petroleum and chemical products in South Korea. Finally, China and Russia should undertake cleaner production division tasks in the production division network, especially for electronic and optical products, construction, and health and social work in China, and in Russia, food and tobacco, wholesale trade, retail trade, land and pipeline transport, real estate activities, public administration and defense, education, and health and social work.

Author Contributions: Conceptualization, Y.W. and R.X.; methodology, Y.W. and X.C.; software, M.S. and X.C.; formal analysis, Y.W. and M.S.; writing—original draft preparation, M.S.; writing-review and editing, M.S. and X.C.; supervision, R.X.; project administration, Y.W. and R.X.; funding acquisition, R.X. All authors have read and agreed to the published version of the manuscript.

Funding: This research was funded by the National Natural Science Foundation of China (NSFC), grant number 71673083.

Conflicts of Interest: The authors declare no conflict of interest.

\section{Appendix A}

Table A1. Sector classification in national I-O analysis in World Input-Output Database (WIOD).

\begin{tabular}{|c|c|}
\hline Sector ID & Sector Name \\
\hline A01 & Crop and animal production, hunting and related service activities \\
\hline A02 & Forestry and logging \\
\hline A03 & Fishing and aquaculture \\
\hline B & Mining and quarrying \\
\hline $\mathrm{C} 10-\mathrm{C} 12$ & Manufacture of food products, beverages and tobacco products \\
\hline $\mathrm{C} 13-\mathrm{C} 15$ & Manufacture of textiles, wearing apparel and leather products \\
\hline C16 & $\begin{array}{c}\text { Manufacture of wood and of products of wood and cork, except furniture; manufacture } \\
\text { of articles of straw and plaiting materials }\end{array}$ \\
\hline $\mathrm{C} 17$ & Manufacture of paper and paper products \\
\hline $\mathrm{C} 18$ & Printing and reproduction of recorded media \\
\hline C19 & Manufacture of coke and refined petroleum products \\
\hline $\mathrm{C} 20$ & Manufacture of chemicals and chemical products \\
\hline $\mathrm{C} 21$ & Manufacture of basic pharmaceutical products and pharmaceutical preparations \\
\hline $\mathrm{C} 22$ & Manufacture of rubber and plastic products \\
\hline $\mathrm{C} 23$ & Manufacture of other non-metallic mineral products \\
\hline $\mathrm{C} 24$ & Manufacture of basic metals \\
\hline $\mathrm{C} 25$ & Manufacture of fabricated metal products, except machinery and equipment \\
\hline $\mathrm{C} 26$ & Manufacture of computer, electronic and optical products \\
\hline $\mathrm{C} 27$ & Manufacture of electrical equipment \\
\hline $\mathrm{C} 28$ & Manufacture of machinery and equipment n.e.c. \\
\hline $\mathrm{C} 29$ & Manufacture of motor vehicles, trailers and semi-trailers \\
\hline $\mathrm{C} 30$ & Manufacture of other transport equipment \\
\hline C31-C32 & Manufacture of furniture; other manufacturing \\
\hline C33 & Repair and installation of machinery and equipment \\
\hline D35 & Electricity, gas, steam and air conditioning supply \\
\hline E36 & Water collection, treatment and supply \\
\hline E37-E39 & $\begin{array}{l}\text { Sewerage; waste collection, treatment and disposal activities; materials recovery; } \\
\text { remediation activities and other waste management services }\end{array}$ \\
\hline
\end{tabular}


Table A1. Cont.

\begin{tabular}{|c|c|}
\hline Sector ID & Sector Name \\
\hline $\mathrm{F}$ & Construction \\
\hline G45 & Wholesale and retail trade and repair of motor vehicles and motorcycles \\
\hline G46 & Wholesale trade, except of motor vehicles and motorcycles \\
\hline G47 & Retail trade, except of motor vehicles and motorcycles \\
\hline $\mathrm{H} 49$ & Land transport and transport via pipelines \\
\hline $\mathrm{H} 50$ & Water transport \\
\hline H51 & Air transport \\
\hline H52 & Warehousing and support activities for transportation \\
\hline H53 & Postal and courier activities \\
\hline I & Accommodation and food service activities \\
\hline $\mathrm{J} 58$ & Publishing activities \\
\hline J59-J60 & $\begin{array}{l}\text { Motion picture, video and television program production, sound recording and music } \\
\text { publishing activities; programming and broadcasting activities }\end{array}$ \\
\hline J61 & Telecommunications \\
\hline $\mathrm{J} 62-\mathrm{J} 63$ & $\begin{array}{c}\text { Computer programming, consultancy and related activities; information service } \\
\text { activities }\end{array}$ \\
\hline K64 & Financial service activities, except insurance and pension funding \\
\hline K65 & Insurance, reinsurance and pension funding, except compulsory social security \\
\hline K66 & Activities auxiliary to financial services and insurance activities \\
\hline L68 & Real estate activities \\
\hline M69-M70 & $\begin{array}{c}\text { Legal and accounting activities; activities of head offices; management consultancy } \\
\text { activities }\end{array}$ \\
\hline M71 & Architectural and engineering activities; technical testing and analysis \\
\hline M72 & Scientific research and development \\
\hline M73 & Advertising and market research \\
\hline M74-M75 & Other professional, scientific and technical activities; veterinary activities \\
\hline $\mathrm{N}$ & Administrative and support service activities \\
\hline O84 & Public administration and defense; compulsory social security \\
\hline P85 & Education \\
\hline Q & Human health and social work activities \\
\hline R-S & Other service activities \\
\hline $\mathrm{T}$ & $\begin{array}{l}\text { Activities of households as employers; undifferentiated goods- and services-producing } \\
\text { activities of households for own use }\end{array}$ \\
\hline $\mathrm{U}$ & Activities of extraterritorial organizations and bodies \\
\hline
\end{tabular}

Table A2. 12 energy commodities in WIOD environmental account.

\begin{tabular}{cccc}
\hline Number & Code & Number & Code \\
\hline 1 & COAL_COKE_CRUDE & 7 & ISTE \\
2 & JETFUEL & 8 & RENEWABLES_NUCLEAR \\
3 & DIESEL & 9 & NATGAS \\
4 & GASOLINE & 10 & OTHGAS \\
5 & FUEL_OIL & 11 & ELECTR_HEATPROD \\
6 & OTHPETRO & 12 & LIQUID_GASEOUS_BIOFUELS \\
\hline
\end{tabular}


Table A3. 22 key sectors in G20 countries.

\begin{tabular}{|c|c|c|}
\hline Sector ID & Short Description & Detail Description \\
\hline $\mathrm{B}$ & Mining and quarrying & Mining and quarrying \\
\hline $\mathrm{C} 10-\mathrm{C} 12$ & Food and tobacco & $\begin{array}{c}\text { Manufacture of food products, beverages and } \\
\text { tobacco products }\end{array}$ \\
\hline C13-C15 & Textiles and leather products & $\begin{array}{c}\text { Manufacture of textiles, wearing apparel and leather } \\
\text { products }\end{array}$ \\
\hline C19 & Coke and refined petroleum & Manufacture of coke and refined petroleum products \\
\hline $\mathrm{C} 20$ & Chemical products & Manufacture of chemicals and chemical products \\
\hline $\mathrm{C} 24$ & Basic metals & Manufacture of basic metals \\
\hline $\mathrm{C} 26$ & Electronic and optical products & $\begin{array}{c}\text { Manufacture of computer, electronic and optical } \\
\text { products }\end{array}$ \\
\hline $\mathrm{C} 27$ & Electrical equipment & Manufacture of electrical equipment \\
\hline $\mathrm{C} 28$ & Machinery and equipment & Manufacture of machinery and equipment n.e.c. \\
\hline $\mathrm{C} 29$ & Motor vehicles & $\begin{array}{c}\text { Manufacture of motor vehicles, trailers and } \\
\text { semi-trailers }\end{array}$ \\
\hline D35 & Electricity and gas & Electricity, gas, steam and air conditioning supply \\
\hline $\mathrm{F}$ & Construction & Construction \\
\hline G46 & Wholesale trade & $\begin{array}{c}\text { Wholesale trade, except of motor vehicles and } \\
\text { motorcycles }\end{array}$ \\
\hline G47 & Retail trade & $\begin{array}{l}\text { Retail trade, except of motor vehicles and } \\
\text { motorcycles }\end{array}$ \\
\hline $\mathrm{H} 49$ & Land and pipeline transport & Land transport and transport via pipelines \\
\hline H51 & Air transport & Air transport \\
\hline I & Accommodation and food service & Accommodation and food service activities \\
\hline L68 & Real estate activities & Real estate activities \\
\hline O84 & Public administration and defense & $\begin{array}{l}\text { Public administration and defense; compulsory } \\
\text { social security }\end{array}$ \\
\hline P85 & Education & Education \\
\hline $\mathrm{Q}$ & Health and social work & Human health and social work activities \\
\hline R-S & Other service activities & Other service activities \\
\hline
\end{tabular}

Table A4. Sectors in which G20 countries have zero output, value added, and final demand in 2014.

\begin{tabular}{cc}
\hline Country & Sector ID \\
\hline Australia & C33, M71, M72, M73, M74-M75, U \\
Brazil & C33, E37-E39, H53, K65, K66, M73, M74-M75, U \\
Canada & C33, G45, J58, J59-J60, K66, M71, M73, T, U \\
China & U \\
Germany & U \\
French & U \\
British & C33, E37-E39, K66, M71, M72, M73, M74-M75, T, U \\
Indonesia & C33, K66, M69-M70, M71, U \\
India & C33, T, U \\
Italy & L68, M73 \\
Japan & C33, E37-E39, H53, J58, J59-J60, K66, M72, M73, M74-M75, T, U \\
South Korea & C21, C33, H53, J58, J59-J60, M69-M70, M71, M73, U \\
Mexico & U \\
Russia & A02, A03, C18, C21, C25, C27, C30, C33, E36, E37-E39, H53, J58, J59-J60, J62-J63, K65, K66, \\
Turkey & M69-M70, M71, M72, M73, M74-M75, T, U \\
USA &
\end{tabular}

\section{References}

1. Kanamura, T. Supply-side perspective for carbon pricing. Quant. Financ. Econ. 2019, 3, 109-123. [CrossRef]

2. IEA. Energy Indicators for Sustainable Development: Guidelines and Methodologies; International Atomic Energy Agency: Vienna, Austria, 2005. 
3. World Bank. GDP at Current US Dollors. Available online: https://data.worldbank.org (accessed on 25 December 2018).

4. Petroleum, B. BP Statistical Review of World Energy Report; BP: London, UK, 2019.

5. Ang, B.W.; Mu, A.; Zhou, P. Accounting frameworks for tracking energy efficiency trends. Energy Econ. 2010, 32, 1209-1219. [CrossRef]

6. Su, B.; Ang, B.W. Structural decomposition analysis applied to energy and emissions: Some methodological developments. Energy Econ. 2012, 34, 177-188. [CrossRef]

7. Su, B.; Ang, B.W. Multiplicative decomposition of aggregate carbon intensity change using input-output analysis. Appl. Energy 2015, 154, 13-20. [CrossRef]

8. Ma, C.; Stern, D.I. China's changing energy intensity trend: A decomposition analysis. Energy Econ. 2008, 30, 1037-1053. [CrossRef]

9. Zhao, X.; Ma, C.; Hong, D. Why did China's energy intensity increase during 1998-2006: Decomposition and policy analysis. Energy Policy 2010, 38, 1379-1388. [CrossRef]

10. Choi, K.H.; Ang, B. Attribution of changes in Divisia real energy intensity index-An extension to index decomposition analysis. Energy Econ. 2012, 34, 171-176. [CrossRef]

11. González, P.F.; Landajo, M.; Presno, M. The Divisia real energy intensity indices: Evolution and attribution of percent changes in 20 European countries from 1995 to 2010. Energy 2013, 58, 340-349. [CrossRef]

12. González, P.F.; Landajo, M.; Presno, M. Multilevel LMDI decomposition of changes in aggregate energy consumption. A cross country analysis in the EU-27. Energy Policy 2014, 68, 576-584. [CrossRef]

13. Voigt, S.; De Cian, E.; Schymura, M.; Verdolini, E. Energy intensity developments in 40 major economies: Structural change or technology improvement? Energy Econ. 2014, 41, 47-62. [CrossRef]

14. Ang, B.W. LMDI decomposition approach: A guide for implementation. Energy Policy 2015, 86, 233-238. [CrossRef]

15. Su, B.; Ang, B.W. Multiplicative structural decomposition analysis of aggregate embodied energy and emission intensities. Energy Econ. 2017, 65, 137-147. [CrossRef]

16. Dietzenbacher, E.; Hoen, A.R.; Los, B. Labor productivity in Western Europe 1975-1985: An intercountry, interindustry analysis. J. Reg. Sci. 2000, 40, 425-452. [CrossRef]

17. Lin, B.; $\mathrm{Du}, \mathrm{K}$. Decomposing energy intensity change: A combination of index decomposition analysis and production-theoretical decomposition analysis. Appl. Energy 2014, 129, 158-165. [CrossRef]

18. Wang, J.; Hu, M.; Rodrigues, J.F. The evolution and driving forces of industrial aggregate energy intensity in China: An extended decomposition analysis. Appl. Energy 2018, 228, 2195-2206. [CrossRef]

19. Hoekstra, R.; Van den Bergh, J.C. Comparing structural decomposition analysis and index. Energy Econ. 2003, 25, 39-64. [CrossRef]

20. Wang, H.; Ang, B.; Su, B. Multiplicative structural decomposition analysis of energy and emission intensities: Some methodological issues. Energy 2017, 123, 47-63. [CrossRef]

21. Zeng, L.; Xu, M.; Liang, S.; Zeng, S.; Zhang, T. Revisiting drivers of energy intensity in China during 1997-2007: A structural decomposition analysis. Energy Policy 2014, 67, 640-647. [CrossRef]

22. Ang, B.W.; Liu, F.; Chung, H.S. A generalized Fisher index approach to energy decomposition analysis. Energy Econ. 2004, 26, 757-763. [CrossRef]

23. Su, B.; Ang, B. Attribution of changes in the generalized Fisher index with application to embodied emission studies. Energy 2014, 69, 778-786. [CrossRef]

24. Su, B.; Ang, B. Multi-region comparisons of emission performance: The structural decomposition analysis approach. Ecol. Indic. 2016, 67, 78-87. [CrossRef]

25. Zhou, X.; Zhou, D.; Wang, Q. How does information and communication technology affect China's energy intensity? A three-tier structural decomposition analysis. Energy 2018, 151, 748-759. [CrossRef]

26. Wiedmann, T.; Lenzen, M.; Turner, K.; Barrett, J. Examining the global environmental impact of regional consumption activities-Part 2: Review of input-output models for the assessment of environmental impacts embodied in trade. Ecol. Econ. 2007, 61, 15-26. [CrossRef]

27. Sato, M. Embodied carbon in trade: A survey of the empirical literature. J. Econ. Surv. 2014, 28, 831-861. [CrossRef]

28. Zhang, Z.; Zhao, Y.; Su, B.; Zhang, Y.; Wang, S.; Liu, Y.; Li, H. Embodied carbon in China's foreign trade: An online SCI-E and SSCI based literature review. Renew. Sustain. Energy Rev. 2017, 68, 492-510. [CrossRef] 
29. $\mathrm{Su}, \mathrm{B}$; Ang, B.W. Input-output analysis of $\mathrm{CO}_{2}$ emissions embodied in trade: Competitive versus non-competitive imports. Energy Policy 2013, 56, 83-87. [CrossRef]

30. Timmer, M.P.; Dietzenbacher, E.; Los, B.; Stehrer, R.; De Vries, G.J. An illustrated user guide to the world input-output database: The case of global automotive production. Rev. Int. Econ. 2015, 23, 575-605. [CrossRef]

31. Ang, B.W.; Choi, K.H. Decomposition of aggregate energy and gas emission intensities for industry: A refined Divisia index method. Energy J. 1997, 18, 59-73. [CrossRef]

32. Ang, B.W.; Zhang, F.Q.; Choi, K.H. Factorizing changes in energy and environmental indicators through decomposition. Energy 1998, 23, 489-495. [CrossRef]

(C) 2020 by the authors. Licensee MDPI, Basel, Switzerland. This article is an open access article distributed under the terms and conditions of the Creative Commons Attribution (CC BY) license (http://creativecommons.org/licenses/by/4.0/). 